\title{
EXPLORING THE USE OF SYSTEMATIC AND HEURISTIC PROCESSING IN THE COURTROOM: THE EFFECT OF EVIDENCE MODALITY ON JURORS’ DECISION- MAKING PROCESSES
}

\author{
by
}

Stuart Freedman,

Bachelor of Arts (Hons) in Psychology, Bishop's University, 2010, Sherbrooke, QC, June 2013

\author{
A thesis \\ presented to Ryerson University \\ in partial fulfillment of the \\ requirements for the degree of \\ Master of Arts \\ in the Program of \\ Psychology
}

Toronto, Ontario, Canada, 2016

(C) (Stuart Freedman) 2016 


\section{AUTHOR'S DECLARATION FOR ELECTRONIC SUBMISSION OF A THESIS}

I hereby declare that I am the sole author of this thesis. This is a true copy of the thesis, including any required final revisions, as accepted by my examiners.

I authorize Ryerson University to lend this thesis to other institutions or individuals for the purpose of scholarly research.

I further authorize Ryerson University to reproduce this thesis by photocopying or by other means. In total or in part, at the request of other institutions or individuals for the purpose of scholarly research.

I understand that my thesis may be made electronically available to the public. 
Exploring the use of systematic and heuristic processing in the courtroom: The effect of evidence modality on jurors' decision-making processes

\section{Master of Arts}

Stuart Freedman

\section{Psychology}

Ryerson University, 2016

The use of technology in the courtroom is increasingly commonplace. While some research has explored how technology may influence jurors throughout the trial itself, there has been little focus on how it might influence jurors during the deliberation period, or whether it affects their verdicts. The current study assessed whether the form of evidence available during the decision-making period, along with the mock juror's level of motivation for the task, affects how trial information is processed and how verdict decisions are made. Mock-jurors $(\mathrm{N}=243)$, half of whom were explicitly informed of the task's importance, watched a video of a murder trial. During the decision-making phase, some jurors were then given the opportunity to review the trial video, transcript, or both before rendering a final verdict. While there were no differences in verdicts as a function of review condition, the amount of content mock-jurors reviewed differed by review condition. 


\section{Acknowledgements}

This thesis is dedicated to my late grandfather, Zaida David. Thank you for all of your encouragement throughout my education, you always pushed me to go further and I am eternally grateful for that.

I would like to thank my supervisor Dr. Tara Burke for her guidance throughout this project. Dr. Burke's expertise, insight, and support gave me the opportunity to study a topic of great interest to me. Her patience through the countless drafts and seas of red was very much appreciated. I would also like to thank my committee members, Dr. Stephen Want and Dr. Becky Choma for their thoughtful suggestions.

I must also thank my lab mates, Sara Cowan and Lesley Zannella for their suggestions and help throughout the process. I promise there are no more questions! Finally, I would like to thank my family for the infinite support they provided me throughout this endeavor. Specifically, I must acknowledge my wife, Rebecca Smith. Her endless patience, support, and help were invaluable along this journey. The time she set aside to discuss research-related ideas and read through drafts was very much appreciated. A sincere thank you to all. 


\section{Table of Contents}

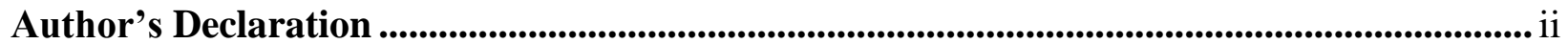

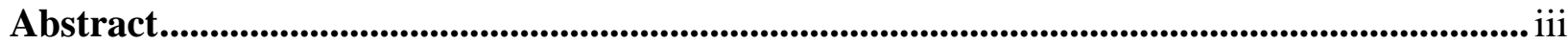

Acknowledgements ................................................................................................................................... iv

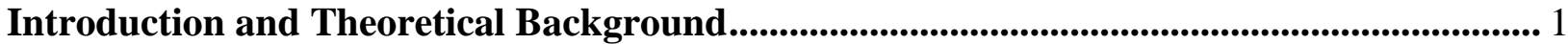

Technology and the deliberation period ............................................................................ 1

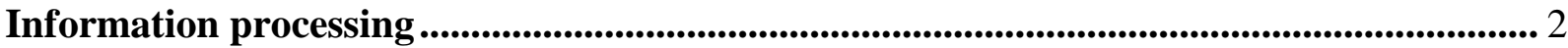

Students' perceived efficacy with different forms of information ........................................... 8

Does technology impact jury decision-making? ........................................................... 13

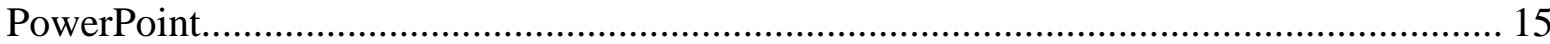

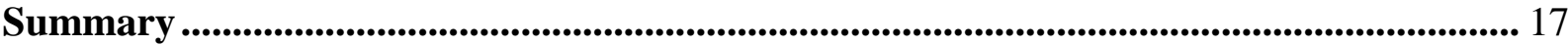

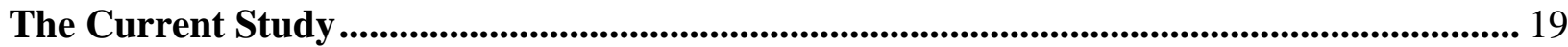

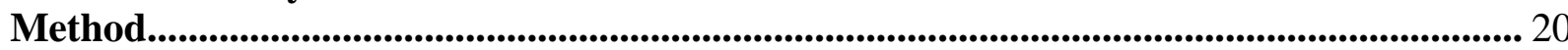

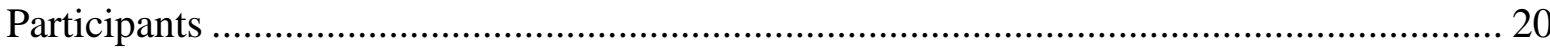

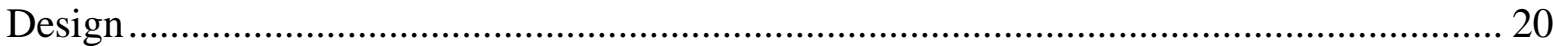

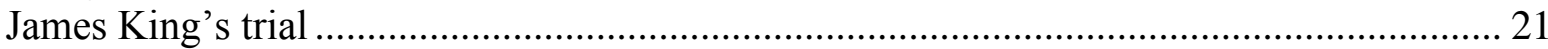

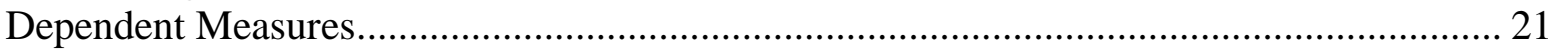

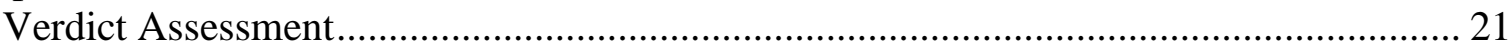

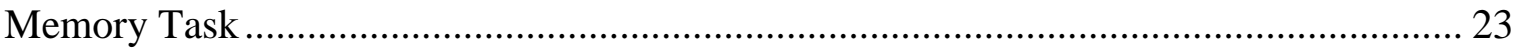

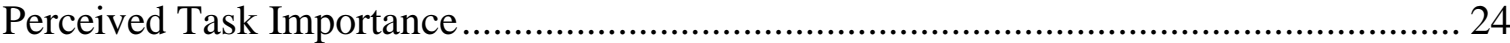

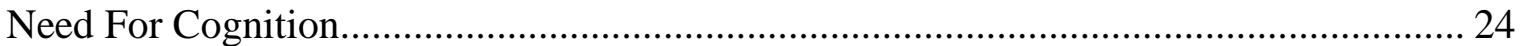

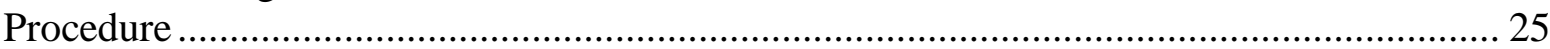

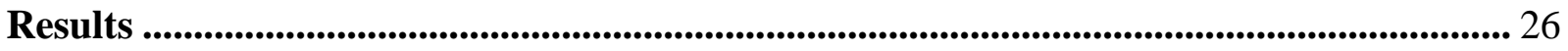

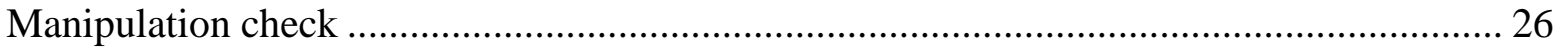

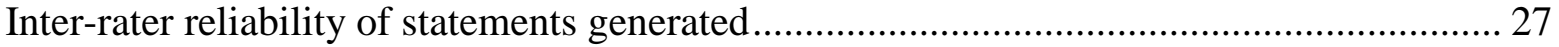

Proportion of systematic statements generated - Motivation........................................... 27

Proportion of systematic statements generated - Modality ............................................ 27

Ability to recall key aspects of the trial - Item difficulty .......................................... 27

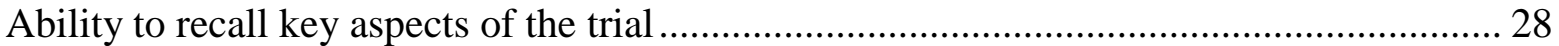

Review of materials - Sections reviewed .................................................................... 29

Review of materials - Time spent reviewing the trial ............................................... 30

Verdict for murder and robbery ........................................................................ 32

Discussion and Summary .............................................................................................. 34

The Effect of Motivation on the Proportion of Systematic Statements Generated........... 34

The Effect of Modality on the Proportion of Systematic Statements Generated ............... 36

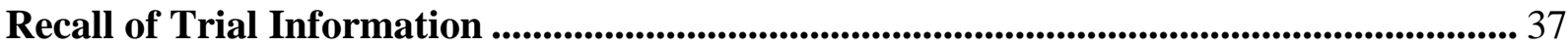

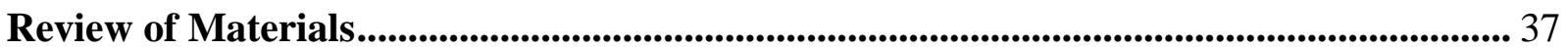

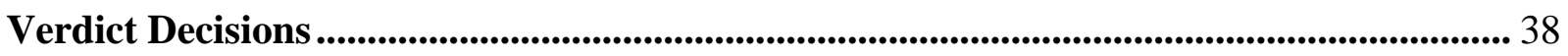

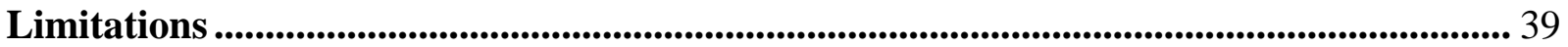

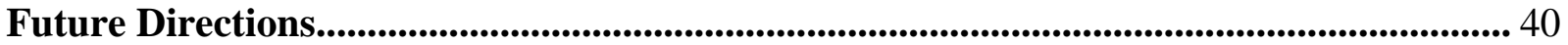

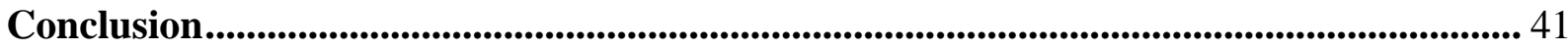

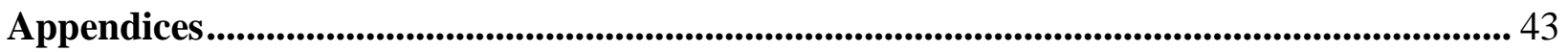

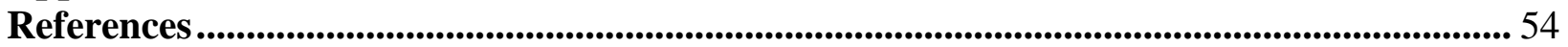




\section{List of Tables}

Table 1. Number of participants per condition.................................................... 20

Table 2. Proportion of participants that reviewed each section by condition....................... 31

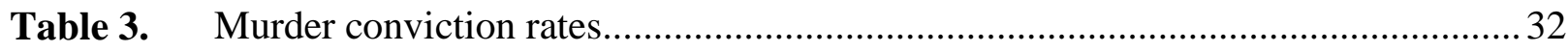

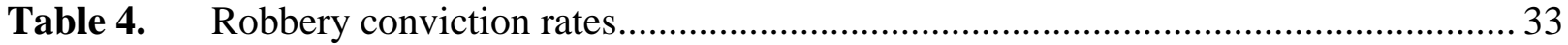




\section{List of Figures}

Figure 1. The effect of motivation and review modality on the proportion of systematic statements generated by participants.........................................................28

Figure 2. The effect of motivation and review modality on participants' ability to recall

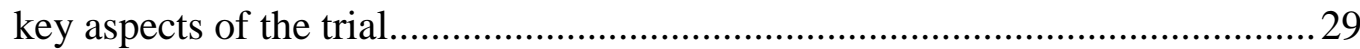




\section{List of Appendices}

Appendix A. Coding guide for verdict reasons.....................................................43

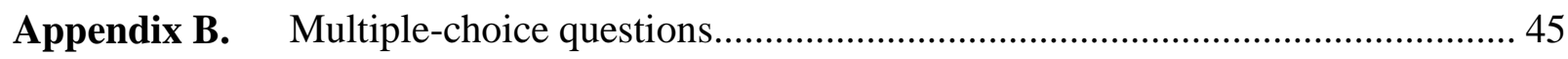

Appendix C. Perceived task importance scale......................................................5 50

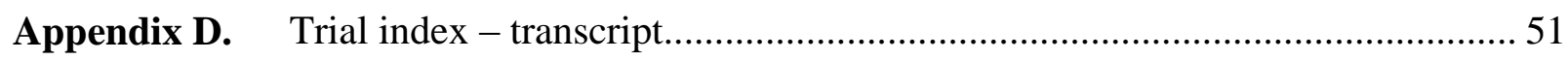

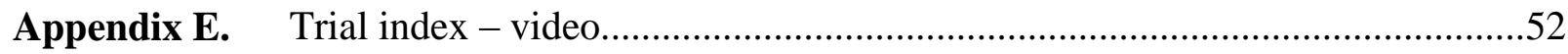

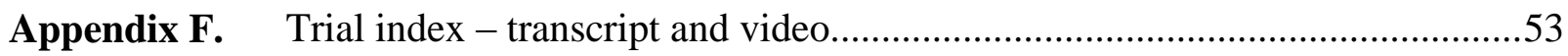


Exploring the use of systematic and heuristic processing in the courtroom: The effect of evidence format on jurors' decision-making.

\section{Introduction and Theoretical Background}

In recent years, the use of modern technologies, such as computers, the Internet, and video presentations, has become increasingly prevalent in courtrooms across Canada and the United States. However, the presence of digital media in the courtroom, and their impact on juries, has not been well studied. The goal of this thesis is to fill this gap and explore whether reviewing two forms of evidence (i.e. video or transcript) impacts the juror decision-making process. Although modern technology is being used in many ways in and around the court system (e.g. Twitter feeds for information, video-conferencing, etc.), for the purpose of this thesis, only the use of modern technology during the deliberation period will be discussed.

\section{Technology and the deliberation period}

Traditionally, after hearing the closing arguments and the judge's instructions, jurors enter the deliberation period, at which time they are sent to a room to discuss the evidence. During the deliberation phase, jurors in criminal trials are asked to remember and understand the information presented during the trial, and then determine how they will weigh the evidence. In essence, they are asked to agree with either the Crown or the Defense's sequence of events (Ellsworth, 1989). The physical evidence jurors are allowed to take into the deliberation room varies widely across different jurisdictions. For example, in many Canadian provinces no physical evidence is allowed into the deliberation room; however, in Quebec, a recording of the testimony made during the trial is permitted. In these cases, jurors are informed that they must listen to the whole recording, not just a portion of the recording (The National Judicial Institute, 
2012). The variation in guidelines concerning the evidence allowed into the deliberation room is also present in the United States justice system, as some courtrooms let jurors review evidence during the decision-making period, whereas others do not. Certain districts across the United States allow for the use of Jury Evidence Recording System (JERS) software. This program allows digital evidence to be reviewed during the decision-making period, after the trial has concluded (Farrell, 2014). Evidence or testimony that is presented during the trial is captured using video cameras and audio systems, then uploaded to the JERS platform. However, whether access to this type of technology has any impact on the juror decision-making process is unknown. Therefore, the current study assesses whether or not mock-jurors' access to various forms of evidence during the deliberation period affects how they process information and ultimately, their decisions. The next section will discuss the impact of various factors on how we process information.

\section{Information processing}

According to the Heuristic and Systematic Model (HSM) of information processing developed by Chaiken in the early 1980s, individuals process information through two routes. Individuals processing information heuristically rely on cues or simple inferential rules in order to reduce cognitive effort when making a judgment. For example, individuals may rely on perceived social consensus and information they already know. Conversely, those who process information systematically are thought to exert greater effort and analyze information prior to making a judgment (Chaiken, 1980). The HSM also suggests that information processing could occur through one or both of the routes and that one route could influence the other (Chaiken $\&$ Maheswaran, 1994). An example of such a combined influence would be jurors thinking of an eyewitness's testimony as more credible due to the consensus of several other eyewitnesses (a 
heuristic judgement), while also analyzing the lawyer's arguments in-depth (a systematic judgement). A related theory that adds to our understanding of information processing is the Elaboration Likelihood Model (ELM) developed by Cacioppo and Petty (1984). The ELM postulates that information is processed along a continuum known as the elaboration continuum. At one end of the spectrum is the peripheral side while the other is the high elaboration end. The peripheral side is characterized by the reliance on simple cues, whereas the high elaboration side of the spectrum is characterized by careful analysis and evaluation of the information. In this model, the degree of motivation and the availability of cognitive resources (e.g. time) dictate whether someone will be more likely to process information using peripheral information or through a careful analysis. For example, if an individual feels pressured to make a quick decision, he/she will fall closer to the peripheral side of the spectrum than the high elaboration side. Although these models of information processing are very similar and were conceived around the same time, the HSM is used in the present study for two specific reasons. First, the HSM views information processing as occurring through one or both routes, whereas the ELM views information processing as occurring along a continuum so does not allow for simultaneous processing through both routes. In a trial setting, the HSM takes into account that jurors could process information both systematically (analyzing arguments) and heuristically (relying on general rules such as, scripts and schemas). Second, the ELM views peripheral processing as occurring due to a lack of an individual's cognitive resources, while the HSM assumes that individuals seek to make cognitively economical decisions by reducing cognitive effort via the use of heuristics. During the deliberation phase of a trial, the jurors' only job is to consider the evidence in order to make a decision. As a result, jurors are not being over-burdened with tasks and should not lack the cognitive resources necessary to make a well-founded decision. 
However, it is still possible that jurors may not carefully analyze all aspects of the trial when making their decision. Therefore, the HSM is better suited for this context.

During a trial, it is hoped that jurors find the task important and are not swayed by the credentials of certain legal professionals. However, these factors may impact how jurors process information. To investigate the extent to which these variables affect information processing, Chaiken and Maheswaran (1994) assessed the impact of task importance and source credibility on the information-processing route used. They asked 367 university undergraduate students how they would rate a fictional new telephone answering system, the XT-100. At first, participants were given one of four versions of a four-page booklet containing a review of the XT-100. Each version differed in terms of task importance and source credibility. Task importance was manipulated by telling participants they were either part of a large sample of people, or a select few whose opinions were highly influential regarding the release of the answering machine. Source credibility was manipulated by telling participants the review either came from Consumer Reports, a magazine that specializes in the scientific testing of new products, or from Kmart employees who were tasked with making a promotional pamphlet. Task importance and source credibility both affected the participants' attitudes, thoughts, motivation, and the number of arguments they could recall in relation to the XT-100. Specifically, Chaiken and Maheswaran (1994) found that when the task was framed as important, participants recalled more important attributes (e.g. the message retrieval and call screening capabilities) versus those in the low task importance condition. In addition, participants in the high task importance condition recalled fewer source related attributes (e.g. Kmart sells inferior products or Consumer Reports magazine is available in the library) than those in the low importance condition. These findings suggest that the perception of the task's importance may affect the decision-making process. Applied to 
the present study, if jurors perceive the task to be important, they may be more likely to exert greater cognitive effort when making their decision, thereby increasing the likelihood of information being processed systematically.

In another study conducted by Chaiken (1980), the effects of task involvement and likeability of an individual were examined to see how these factors affect information processing. Chaiken (1980) asked 207 undergraduate students to take part in what they thought were two face-to-face testing sessions. However, in reality this experiment involved one testing session with a follow-up phone call. During the testing session, participants were instructed that they would be interviewed about one of two unrelated discussion topics, either their opinions on less sleep per night, or a "trimester" academic term system instead of their current two-semester year. In order to get a better idea of what their interview would consist of, participants were given a fake transcript from a "related study" with the same topics. Within these transcripts, a university administrator from the school provided a persuasive message comprised of either two or six arguments that advocated for either one of the topics. Embedded within this administrator's purported arguments was their answer to the question "how do you like working with undergraduates?" which was the manipulation of the likeability of the source. Finally, students were asked to complete a questionnaire on their reactions to the fake interview and told they would be contacted later on in the semester for the second session.

Students in the high response involvement condition received a simulated interview transcript on the same topic they were assigned (i.e. those assigned to the sleep condition were given fake transcripts on sleep); whereas those who received a different topic were considered the low response involvement condition (i.e. those initially assigned to the sleep condition read transcripts on the other topic). Communicator likability was manipulated via the administrators' 
answer to the question of whether or not they liked working with undergraduates. For those in the likable condition, the administrator said that they enjoyed working with undergraduates because they are mature. Conversely, those in the unlikeable condition were told that the administrator did not like working with undergraduates because they are immature.

Chaiken (1980) hypothesized that individuals in the high involvement condition would use the systematic route of information processing, scrutinizing the arguments, and would be relatively unaffected by the communicator's likability (a heuristic). Conversely, those in the low task involvement group were expected to use the heuristic route, and therefore would more likely be influenced by the likability of the communicator. Both hypotheses were supported. Participants in the high involvement group (i.e., congruent scenario) were, for the most part, unaffected by the likability of the communicator. Participants' opinions were also stronger when presented with six arguments compared to only two, as indicated by how strongly they agreed with the overall position stated in the persuasive message. Individuals in the low involvement group were more likely to agree with the position of a likeable individual, though their opinions were stronger when presented with six arguments as well. Participants in the high involvement condition also spent more time reviewing and thinking about the arguments and less time thinking about the communicator's personal characteristics versus those in the low importance condition. In sum, these results indicate that one of the main factors underlying whether individuals process information systematically or heuristically is their level of involvement with the task. Task involvement is important in relation to the current study, as it is hoped that jurors are processing trial information systematically and engaging with the material in order to produce a well-founded verdict. As a result, juror involvement needs to be taken into account when investigating the use of digital technology during the decision-making period. 
In a follow-up study, Chaiken (1980) tested combinations of high or low task importance, with communicator likeability and the number of arguments presented to 80 undergraduate students. Once again, students were given a four-page booklet advocating for a change towards a tri-semester academic year. Students were then asked if they preferred to change their current schedule from a two semester year to a tri-semester year after being shown one argument from a likeable individual or five arguments from an unlikeable individual. Personal relevance was manipulated by telling students that, if approved, the university would change the current schedule to the tri-semester schedule for the beginning of the following academic year while others were told that the change would only be implemented a couple of years later. It is important to note that prior to this study, when asked, students generally disagreed with the proposed change to a tri-semester system. Chaiken hypothesized that participants in the high personal relevance condition would be persuaded by five arguments from an unlikable communicator, rather than one argument from a likable individual. It was thought that individuals in the high personal relevance condition would be processing information systematically, and would therefore be less influenced by the communicator's likeability and more interested in his arguments. In the low personal relevance condition, participants were expected to have a greater opinion change when there was only one argument from a likable communicator versus five from an unlikable communicator. This was expected because individuals who have less personal relevance to the issue would employ a heuristic route to process information and heavily rely on the likability of the communicator rather than their argument. As expected, participants in the low personal relevance condition found a likable individual more persuasive than an unlikeable person. 
As could be seen from the above literature there are many factors affecting whether an individual processes information systematically or heuristically. Included in these factors are the extent to which someone views the task as important and their level of involvement in the task (Chaiken \& Maheswaran, 1994). It is clear that individuals employing a systematic thought process base their decision upon sound arguments as they expressed a need to be well informed, took more time to think about the arguments made, and are less influenced by the communicator's likeability over those employing a heuristic route (Chaiken and Maheswaran, 1994).

Jurors are being trusted to make decisions that greatly impact the lives of those on trial. Given the importance of this task, we would expect that jurors are engaging with the trial information and employing a systematic approach to processing information; that they are carefully analyzing key arguments, weighing the evidence, and considering the expertise of those presenting the information. As a result, we hope that jurors have a good understanding of the trial events and are able to produce a well-founded verdict.

\section{Students' perceived efficacy with different forms of information}

Implicit in the HSM theory is that individuals seek to make economical decisions, meaning that they try to minimize the amount of cognitive effort needed to arrive at a decision (Todorov, Chaiken, \& Henderson, 2002). However, there are certain moderators that influence the amount of cognitive effort an individual exerts, such as the degree to which they are involved in a task. This poses a threat to the legal system as it could influence the way jurors' process information and their understanding of the trial. One factor that may influence jurors' involvement and their perception of the task could be how efficacious they view themselves with different forms of information when reviewing the evidence. For example, jurors may perceive 
themselves as being more efficient when using digital media to review a trial compared to reading a transcript. However, their choice for using such media may be due, in part, to them wanting to reduce the amount of cognitive effort needed to complete the task or make the decision. The lack of effort would then reduce the likelihood of jurors processing information systematically. Although the focal point of this thesis is to explore the impact of reviewing evidence on the way information is processed, not much research exists on this specific topic. It is therefore important to review studies that more generally look at whether the modality used to present information can affect processing. To that extent, the following section will look at whether students perceive a difference in their ability to understand information based on the form information is presented in.

Salomon (1984) assessed whether students found it easier to learn from watching a silent TV program versus reading about it. To do so, he first surveyed 124 sixth-grade students on their perceived learning ability when information was presented in either print or video format. Salomon asked students questions, such as "how easy would it be for you to solve a math problem from a TV program or a book?" The answers were rated on a Likert-type scale ranging from one (very easy) to five (very difficult). One week later, Salomon returned to the school for a second testing session and randomly assigned the same 124 students to either a television condition or a print condition. Both the television program and text were based on the same story of an artist living by a lake who sells a piece of their artwork to an art dealer who had landed their plane on a nearby lake. After viewing the program or reading the text, students were given a brief questionnaire assessing the degree of effort they exerted. Lastly, students were tested on their ability to make an inferential assessment of the story and their ability to recognize facts from within the program or text. Inferential assessments were based on four questions that asked 
participants about features of the story that were not explicitly shown or discussed in the TV program or the text, such as "What did the artist think when they got paid?" The recognition test consisted of ten multiple-choice questions pertaining to explicitly shown or described features.

Salomon had four main hypotheses; however, three of them are of particular importance to this thesis: (a) It was believed that students would attribute greater realism to TV than print and rate their perceived self-efficacy as better with TV than print; (b) Those in the TV condition would exhibit less inferential learning; and (c) The perceived self-efficacy for those in the TV condition would be negatively correlated with the amount of mental effort exhibited and students' ability to infer information about the story. Conversely, for those in the reading condition, there would be a positive relationship between perceived self-efficacy, the amount of mental effort exerted, and the amount of learning.

Results from this study indicated that students perceived themselves as being more efficacious when using a video compared to a text to learn information. However, students in the reading condition outperformed students in the watching condition on the inferential task (Salomon, 1984). In addition, for those in the print group, perceived efficacy was positively correlated with achievement and effort compared to the television group, where perceived efficacy was negatively correlated with overall achievement and effort. The results of this study suggest that jurors may believe they are more efficient learners when using video based information, however, they may develop a more thorough understanding of the trial when using text-based material while completing their review.

In an exploratory study with a small sample size, Choi and Johnson (2005) assessed perceived learning differences in using video or text among graduate students enrolled in an 
online course. Choi and Johnson had two main research questions: (a) whether or not perceived learning differs between video and text based instruction, and (b) whether or not students are more or less motived by one modality compared to the other. To answer these questions, the authors asked students about their perceptions of understanding and retention of the material presented to them. As for motivation, students' attention, perceived task relevance, and confidence were tested. Except for perceived retention of material, the above-mentioned measures were tested using two Likert-type scales assessing motivation and perception of learning, while retention of material was tested at the end of the semester (as opposed to after the lesson) using an open-ended question. Participants first experienced the video-based content followed by the text-based material of the module. After experiencing both types of information modalities, students were asked to rate their perceived learning with both forms of information presentation. In terms of perceived understanding, there was no difference in students' perceived understanding between video and text-based material. However, students' perceived the videobased content as more memorable compared to the text-based instruction. In terms of motivational measures (i.e. attention, perceived task relevance, and confidence) students perceived themselves as being better able to attend to the video-based content than the traditional text-based content. Despite the small sample size, the overall results are congruent with previous literature indicating that students perceive video-based learning as more effective compared to text-based learning.

To further assess the relationship between modality and memory, Sundar (2000) conducted a study assessing participants' ability to recognize and recall information on a news website, as well as their perceptions of that website. Sixty undergraduate students viewed a news website created for this study that contained three news articles taken from various news sources 
(e.g CNN) with advertisements posted on the side of the screen. Although the content on the website remained constant, Sundar varied the modality used to present the information. Some participants were given access to a website that, in addition to the text, contained pictures, audio, or video downloads. After viewing the website for 15 minutes, participants' ability to recall and recognize the information presented on the website and in the ads was assessed. For the website content, there were three recall questions for each of the three news stories and four items that assessed recognition. To assess advertisement content, there were two recall questions and three recognition questions. In addition, participants were asked to provide an evaluation of the website and answer questions about their perception of the content. For these dependent variables, there were 13 items placed at the beginning of the questionnaire (i.e. before the memory questions).

Results suggested that individuals were better able to recognize key information when only reading the information or when a picture was present in addition to the written content, compared to those who viewed the material using a video. Interestingly, this relationship was reversed for advertisement recognition; individuals better recognized information about the advertisement on the side of the screen when watching the material compared to reading it. Additionally, Sundar found that when asked about their perceptions of the website, participants in the picture-with-audio condition rated the website in a more negative manner compared to those in the text-with-picture condition. There were no significant differences in participants' evaluations of the website between any of the other conditions. In relation to the current study, these findings are particularly interesting as they suggest that jurors who review evidence via video compared to text may pay more attention to extraneous details rather than key information. 
In sum, the above research found that students perceived themselves as being more efficacious with video-based information versus text-based information. However, as revealed in Salomon's (1984) study, this perceived efficacy is problematic as students have a difficult time making inferential links to a story when watching it versus reading it. In addition, students' ability to recognize pertinent information was superior when reading a text compared to watching a video (Sundar, 2000). Within the context of a trial, these studies suggest that jurors may perceive themselves as being more efficacious with video based information but perform better with text based information. In relation to the HSM, these findings could be explained by the assumption that people try to reduce cognitive effort when making a decision. If jurors view themselves as being more efficacious with video as a way of reducing cognitive demand they may not carefully scrutinize the information presented during the trial.

Knowing which modality individuals perceive themselves as being more efficacious with is an important aspect to figuring out whether reviewing evidence via video or transcript is of concern in terms of how individuals are processing the information. To better understand this information within the context of a trial we must explore the extent to which different forms of information impact jurors' decision-making. Therefore, the next section will look at the impact of technology on jurors' decision-making.

\section{Does technology impact jury decision-making?}

Davis, Markus, and Walters (2006) conducted a study that assessed the credibility of suspect statements. For the purpose of their paper partial suspect statements known as 'utterances' were used. These utterances were presented to participants in one of four ways: a content-only transcript, which only included words from the speaker; a verbatim transcript, which included bridging or filler expression and word repeats; an audio recording; or a video 
recording (with audio). Researchers tested 120 graduate students enrolled in either a criminology or forensic psychology program. The students were presented with 20 utterances by 10 suspected criminals and were asked to judge the credibility of each utterance. The utterances chosen were ones that could be corroborated as truths or lies from the investigation of that case. Of the two utterances chosen per suspect, one was a truth while the other was a lie. Although the modality was different for each condition the procedure was relatively similar. Participants read, watched, or listened to the utterances and were instructed to judge them as truthful or deceitful. Participants were unaware of the number of statements that were truthful or deceitful; however, they were made aware that two statements were used from each suspect and that each suspect told zero, one, or two lies. Overall, participants in the verbatim condition were more accurate in judging a true statement as true, whereas judges in the audio condition were most accurate at detecting lies.

Davis and colleagues' (2006) first hypothesized that deception detection would be lowest when presented with content-only transcripts versus the other three conditions. The first hypothesis was based on previous findings that suggested audio and audio/video judges to be more accurate when judging suspect statements than transcript judges (DePaulo, Lanier, \& Davis, 1983, as described by Davis et al. 2006). This hypothesis was supported, as individuals in the content-only transcript condition had the lowest overall accuracy for detecting lies. No differences in deception detection were found between the other conditions (i.e. audio vs. video vs. verbatim transcripts). In addition, judges' confidence in their ability to detect deception was measured. While not a formal hypothesis, the authors expected that there would be no relationship between confidence and accuracy or confidence and modality. As expected, there 
was no relationship between confidence and modality. Contrary to their prediction, however, there was a weak positive correlation between confidence and accuracy.

It is also noteworthy that within the video condition some stereotypical cues of deception were included (e.g. gaze aversion), and although individuals believed they indicate deception, in reality they do not. These findings play an interesting role in the case of a trial. The findings indicate that jurors would be more accurate in detecting truthful and deceitful statements when subjected to audio, video, or audio-like cues. However, as found in the Sundar (2000) study, when presented with information in the form of a video, individuals may be less likely to process pertinent information.

As discussed earlier, one way of presenting data to jurors is through the use of PowerPoint. Although this form of presenting information is mainly used in the courtroom, a PDF of the PowerPoint could be uploaded to the JERS system, where jurors may view it during the deliberation period. Therefore, it is important to understand its impact on the juror decisionmaking process.

PowerPoint. In a three-part study exploring the use of technology in the courtroom, Park and Feigenson (2013) investigated the impact of PowerPoint use on jurors' decision-making process. In Study one, Park and Feigenson used a 2 (plaintiff use of PowerPoint: yes, no) X 2 (defendant use of PowerPoint: yes, no) design where participants were shown one of four versions of a real court case where a railroad company was being sued for racial discrimination. The clips of the case shown to participants included the opening statements of both the plaintiff and the defendant. These clips were modified so that either the plaintiff or the defendant or both parties were shown to have used PowerPoint or not during the trial. After viewing one of the four videos, participants were asked to complete a questionnaire assessing the defendant's liability 
and a memory task. Park and Feigenson hypothesized that the judged liability of the defendant would be lowest when only the defense used PowerPoint and highest when only the plaintiff used PowerPoint. This hypothesis was supported. When the plaintiff used a PowerPoint presentation, mock jurors held the defendant as more responsible than when the plaintiff did not. In addition, when one side used PowerPoint, participants were more likely to correctly recall that side's statistics as presented in the slides.

Study two contained two subparts (Park \& Feigenson, 2013). In the first part (a), a similar design and procedure to the first study was used except only the plaintiff's use of PowerPoint was manipulated as well as the order of the opening statements. The instructions given to participants were slightly altered to ensure the burden of proof was understood and three recall questions were added. Confirming what was found in the previous study, when the plaintiff used PowerPoint the defendant was judged as more liable. The plaintiff's lawyer was also seen as better prepared, more competent, and more persuasive when (s)he used PowerPoint versus when (s)he did not. They found that found mock jurors recalled more of the plaintiff's statistical evidence when using PowerPoint compared to no PowerPoint use. In the second part (b) of experiment two, the use of PowerPoint by the defendant was manipulated. Once again, when the defendant used PowerPoint their lawyer was judged as better prepared, more competent, and persuasive compared to when they did not use the technology. Participants were also better able to recall the statistical information presented by the defendant when they used PowerPoint compared to when they did not use it.

These results indicated that the use of PowerPoint impacted mock jurors' ability to recall information as well as their perceptions of the lawyers (Park \& Feigenson, 2013). Using the ELM framework, Park and Feigenson (2013) explain that the use of PowerPoint can impact both 
central and peripheral processing. Central processing requires cognitive effort to attend to the content of a message, which is evident in their results as mock-jurors were better able to recall and understand statistical information when PowerPoint was used. Conversely, peripheral processing requires relatively less cognitive effort and the reliance on source characteristics to judge the message, which is displayed in mock-jurors' perceptions of the lawyers (e.g. preparedness). I would suggest that these findings could also be interpreted using the heuristic and systematic model. If mock-jurors who view PowerPoint presentations are better able to recall and understand statistical information, this suggests they are processing information systematically as being able to recall and understand complex information requires effort. Conversely, heuristic processing is evident when jurors allow their perceptions of the lawyers, rather than the evidence, to influence their decision.

\section{Summary}

It is seen throughout the literature that motived and engaged individuals will be more likely to think about and scrutinize information (Chaiken, 1980; Chaiken \& Maheswaran, 1994). This increased level of engagement and motivation will likely lead to an increased use of cognitive resources and should result in a decision that is well thought out. As mentioned earlier, Chaiken (1980) posits that an increase in motivation is accompanied by the use of the systematic route to process information. It is therefore hoped that jurors will be engaged and motivated to produce a well-founded verdict, and thus process information systematically.

During a trial, jurors may be exposed to a host of presentation modalities and since task engagement is a major determinant of systematic processing, it is vital to explore the relationship between the individuals' level of engagement and the modality used. In Salomon's (1984) study, discussed previously, students thought they learned better from watching a program versus 
reading about it. However, they struggled to make inferential links when watching the program (Salomon, 1984). In another study, students performed better on memory tasks when presented with text-based information compared to video and audio-based information (Sundar, 2000). Although students perceived themselves as better learners when given a video versus text, they performed better with text-based information. One possible explanation is they may view the video as requiring less cognitive effort and consequently, process the information heuristically. On the other hand, it has been found that jurors are better judges of statement accuracy when given audio or audio/video cues (Davis et al. 2006).

From these findings, it is clear that people perceive themselves as being more efficient with video than text, and in the case of judging statements their perceptions may be true. However, this finding, in part, could be due to the nature of the task participants were asked to complete. Davis and colleagues asked participants to simply make a judgment about a partial statement; whereas in the other studies, participants were asked to understand and memorize information - similar to what we hope jurors would do. In the case of a trial, if offered a choice between a video or a trial transcript to review, jurors may choose the video because they perceive it to be easier to understand; this may lead to a decreased likelihood of them processing information systematically. To date, no research has explored the role of technology choice in the context of a trial, nor whether having access to different forms of evidence during the deliberation period impacts how jurors make their decisions. Therefore, this thesis explores whether having access to the evidence for review (or not) in either the form of a video or transcript influences mock jurors' decisions. 


\section{The Current Study}

Broadly, the goal of this research was to explore the impact of technology on jurors' decisions. More specifically, the aim was to assess whether manipulating motivation and the modality of information available during the decision-making period affects how jurors process information and the decisions they make. Mock jurors watched a trial and, prior to rendering a verdict, they had a chance to review the proceedings of the trial, or not. Those who were given the opportunity to review either received a video, a written transcript, or had the option to use both in order to complete their review.

The following hypotheses were tested:

1) It was hypothesized that motivated mock-jurors would be more likely to process information systematically, regardless of modality used to review the trial. This was because Chaiken (1980) has identified motivation as a factor that increases the likelihood of processing information systematically. Information processing was measured using statements provided by participants in support of their verdict.

2) I hypothesized that the proportion of systematic processing for mock-jurors in the transcript condition would be different compared to those in the video condition or the combined [video and transcript] condition. There is insufficient empirical evidence to predict a direction for this effect.

3) I predicted that mock-jurors who were given the opportunity to review the evidence would perform better on a memory task compared to those who were not given the opportunity to review the evidence, regardless of modality. 


\section{Method}

Participants. One participant did not finish the study. Therefore, the sample consisted of 243 participants, 196 women (81\%), 44 men (18\%), and two individuals who classified themselves as "other". Participants were recruited through the online participant pool at Ryerson University and ranged in age from 16 to $58(\mathrm{M}=20.82, \mathrm{SD}=5.55$; see Table 1 for the number of participants per condition). Participants were awarded one and a half credits towards their Introductory Psychology course.

Table 1

\begin{tabular}{ccccc} 
Number of participants per condition & & \\
\hline Motivation & No review & Transcript & Video & Transcript and video \\
\hline Task important & 33 & 31 & 25 & 33 \\
Not important & 26 & 33 & 32 & 30 \\
\hline
\end{tabular}

Design. This study was a 2 (Motivation: task important vs. not important) X 4 (Modality: transcript vs. video vs. combined vs. no review control) between-participants design. On average, there were 30 participants in each condition, ranging from 25 to 33 participants per cell. As identified by Chaiken (1980), and Chaiken and Maheswaran (1994), task importance is a key component that affects whether someone processes information systematically or heuristically. Therefore, the first independent variable manipulated the participant's perception of the task's importance. The experimenter told participants in the task importance condition, "the data collected from this study will form the basis of a Master's thesis and is part of a grant. So it is really important that you take the study seriously. Please pay attention to the trial and, later, when you are answering the questions about the trial, please read all the questions carefully" while those in the non-important condition did not receive any instructions regarding task's importance. To assess the question of whether or not the modality in which the evidence was 
presented affected decision-making, the second independent variable was modality of review, for which there were four levels: Written transcript, video, video and transcript together, and a control group who did not review the trial. After all participants watched the trial, those in the review conditions were given access to the trial, for review, via one of the above-mentioned modalities.

James King's trial. The trial participants were asked to watch was that of James King, a man accused of committing multiple murders in the process of robbing a bank. King was charged with these crimes as he had an intimate knowledge of the bank's layout because he was a former guard, had the same type of gun which was used during the bank robbery and murder, and matched the description of the bank robber. However, at the time of the crime, King had an alibi and claimed to be traveling to a chess club, which was not near the bank. He also claimed that he disposed of his gun months before the crime was committed and that many people could match the description of the bank robbery. The state's witness, who was also a friend and fellow guard at the bank, confirmed this. In addition, none of the eyewitnesses were able to identify King during the first photographic line-up. Ultimately, there was insufficient evidence to convict him of the crime.

Dependent Measures. To measure the extent to which modality and motivation affected decision-making within the context of a trial the following dependent variables were assessed: (1) verdict assessment, (2) recall of trial details (memory), and (3) perceived task importance. Along with those measures, participants' need for cognition was tested.

Verdict Assessment. Participants were asked to first indicate whether they found the defendant not guilty or guilty and then rate their confidence in their verdict. Confidence was 
rated on a Likert-type scale ranging from one (not confident) to seven (extremely confident). They were then asked to provide their reasons for choosing that verdict. A detailed coding guide was developed (see Appendix A) and participants' statements were coded as being either systematically or heuristically based. Any statements that appeared to be based on specific facts or arguments were coded as being systematically generated. Four subcategories emerged: First was strength of the evidence relating to the case. An example of this was whether or not the participant agreed with King's timeline of events, or whether the fingerprints found at the scene of the crime matched King's. Second were persuasive arguments (including testimony).

Persuasive arguments were statements that participants gave in which they based their verdict on King's alibi or other testimony. For example, the testimony provided by the witness where they incorrectly recalled facial features of defendant (i.e. his mole). Third were fact-based arguments. This type of statement was verifiable, for example, the date King opened a larger safety deposit box or the length of time he worked at the bank. The last category was other. This category accounts for statements that did not fall directly under any of the above categories but where a systematic thought process was shown. An example would be a participant who believed King to be not guilty based on the burden of proof.

Any statements that were of a more personal 'feeling' or where information external to the case was used were coded as Heuristic. Five subcategories emerged: First were personal characteristics of those involved in the trial. An example would be a participant basing their decision on how King looked - whether or not he looked like a person who can commit the crime. Second were statements assumed to be true based on the credentials of the individual (e.g. expert witness). Third was the use of consensus. An example would be a participant who believed King was guilty based on the number of eyewitnesses who testified. Statements in this 
category were not based on arguments presented by the eyewitnesses but rather the number of eyewitnesses present. Fourth were statements based on the participants' prior knowledge, regardless of whether they were true or false in the context of this case. For example, whether participants believed King committed the crime to finance his trip to Las Vegas (based on their belief that a trip to Las Vegas is expensive). Last were judgments based on the perceived veracity of the statement. For example, mock-jurors who judged King as guilty because they found certain aspects of the trial "unusual". In addition to the systematic and heuristic categories, a third category was developed in order to account for statements that did not make sense in relation to the trial or where the participant did not write anything. After coding each statement as systematic or heuristic, the proportion of systematic and heuristic statements generated by each participant were added up then averaged for each of the eight conditions.

Memory Task. Participants were asked to answer 25 multiple-choice questions, each with four choices, with only one choice being correct. These questions assessed their ability to recall key information about the trial (see Appendix B). The questions were based on various aspects of the trial, such as, the sequence of events, information about the case, and personal characteristics about the people involved in the trial. For example:

1) How long did King work at the bank for?
A. Less than 5 years
B. Between 5 and 10 years
C. Between 10 and 15 years
D. More than 16 years 
2) When King went downtown on the day of the robbery, where did he claim to have gone?
A. The chess club
B. The bank to get a larger safety deposit box
C. The grocery store
D. To shop for his wife

Perceived Task Importance. The participant's perceived task importance was measured using seven questions, such as "How enjoyable did you find the task?" and "To what extent were you focused on the information presented during the trial?" (see Appendix C). Respondents answered these questions using a Likert-type scale ranging from one (not at all enjoyable/ focused) to seven (extremely enjoyable/ focused). This variable was used as a manipulation check to assess whether those who received explicit instructions indicating the importance of the task, perceived the task as more important compared to those who did not receive the instructions.

Need For Cognition. Originally developed by Cacioppo and Petty (1982), the need for cognition scale measures the degree to which people enjoy partaking in effortful cognitive activities. The current study used a revised scale developed by the Wabash National Study of Liberal Arts Education. Scores on the revised scale correlate highly with those on the original scale, $r=.95, p<.001$ and account for more variance within the single factor (need for cognition), $37 \%$ compared to $27 \%$ on the original scale. The revised scale was also found to be highly reliable $(\alpha=.90)$ compared to the original scale $(\alpha=.91)$ (Cacioppo, Petty, \& Kao, 1984). This measure was included in the current study as a way to differentiate between 
participants who were more likely to process information systematically from those who were more likely to do so heuristically.

Procedure. After signing up to take part in the study, participants were asked to attend a single testing session in a testing lab in groups ranging from one to four, with the total time taken to complete the session being approximately ninety minutes, half of which was allotted to watching the trial. Upon arriving at the lab, participants were seated at opposite ends of the table to ensure they could not see one another's answers. The researcher first verbally explained the details of the study and then asked the participants to read and sign the consent form. At that time, it was made clear to the participant(s) that, if for any reason they felt uncomfortable completing the experiment they were allowed to withdraw from the study without penalty. After signing the consent form, participants were read a cover story that briefly explained the nature of the trial they were about to watch. Within these instructions was the task importance manipulation; half were explicitly told, "the data collected from this study will form the basis of a Master's thesis and is part of a grant. So it is really important that you take the study seriously. Please pay attention to the trial and, later, when you are answering the questions about the trial, please read all the questions carefully." Participants then watched the trial of James King.

After participants finished watching the trial, those in the review conditions (i.e. video, transcript, or both) were offered time to review the trial. To ensure the study was not arduous and that participants would not quit part way through, it was decided that a ten-minute review period would be sufficient and would also keep the study within a reasonable time frame. Prior to starting their review, participants were either given access to the trial video, a written transcript, or had access to both the video and transcript. At that time, they were given a sheet of paper, which indexed the trial, allowing them to quickly find the sections they wished to review (see 
Appendix D to F). Participants were asked to circle the sections they reviewed (e.g. King's testimony) and were told that these ten minutes were solely for them to get a better understanding of the trial, as they would be asked questions about it later on. After completing their review (if in the review condition), the time taken was recorded.

Last, participants were asked to complete an online survey that contained the dependent measures. Of these measures, participants were first asked to complete the verdict assessment form, rate their confidence in their verdict, and provide their reason for choosing the verdict they did. For their reasons, participants were simply asked to list the key reasons for choosing the verdict they did. Finally, participants were asked to fill out the rest of the questionnaires, which assessed their memory for trial details, perceived task importance, and need for cognition. Before leaving, participants were thoroughly debriefed and thanked for their time.

\section{Results}

Manipulation check. The perceived task importance (PTI) questions were used to verify that the motivation manipulation was successful. The PTI scale was calculated after performing a reliability analysis on the relevant questions. There were 7 questions, rated on a 7 point Likerttype scale. An initial reliability analysis revealed a Cronbach's alpha of .782. However, item 4 (How important is it for real jurors to pay attention to all the facts?) had an inter-item correlation below .3 threshold and was therefore removed, increasing Cronbach's alpha to .801 .The final scale consisted of 6 items (please refer to Appendix E for a list of items) with the total score ranging from 6 to 42 . A t-test indicated that the task importance manipulation was successful, $t(237)=3.933, p<.001$. Specifically, those in the motivated condition $(\mathrm{M}=34.11, \mathrm{SD}=4.96)$ scored higher on the PTI scale compared to their non-motivated counterparts $(\mathrm{M}=31.42, \mathrm{SD}=$ 5.58). However, all participants scored relatively high on this scale. 
Inter-rater reliability of statements generated. A research assistant second-coded all the participants' answers to the open-ended question of the verdict assessment, which asked them to provide their reasons for choosing the verdict they did. These statements were coded independently from the author and the initial overall Kappa value was .781 (overall percent agreement was $89.3 \%$ ). This value suggests substantial agreement between raters (Landis \& Koch, 1977). After discussion all discrepancies were resolved.

Proportion of systematic statements generated - Motivation. Hypothesis one predicted that motivated mock-jurors would be more likely to process information systematically, regardless of modality used to review the trial. Hypothesis one was not supported, $t(239)=1.43, p=.154, d=.25$ (see Figure 1$)$. However, a non-significant trend was found, $\mathrm{r}_{\mathrm{pb}}=.124, p=.056$, which indicated that participants in the task importance condition provided more systematic statements $(\mathrm{M}=73 \%, \mathrm{SD}=25 \%)$ compared to their non-motivated counterparts $(M=68 \%, S D=28 \%)$. Despite the high proportion of systematic statements, participants generated 21 statements, which suggested that an innocent person would not need an alibi.

Proportion of systematic statements generated - Modality. Hypothesis two was exploratory in nature but predicted that the proportion of systematic statements generated would be different between the review conditions. No significant effect of modality was found on the proportion of systematic statements provided, $F(3,233)=.310, p=.818$, partial $\eta^{2}=.004($ see Figure 1).

Ability to recall key aspects of the trial - Item difficulty. To ensure the multiplechoice questions were a fair assessment of recall ability, the difficulty level of the questions was 
assessed. To determine the items' difficulty level, the total number of responses was divided by the number of correct responses. If the ratio was below .5, a point-biserial correlation was conducted. Items below this threshold that had no significant correlations were not included in the analysis as they did not discriminate between participants who did well and those who did not. Out of the 25 questions, four were deleted, making the total possible correct answers being 21. These four questions appeared to be too difficult for most participants to answer correctly. In comparison to other questions, these four tended to involve information that was presented quickly during the trial, was not repeated, or was not a key detail (see Appendix B for deleted items).

\section{Systematic Statements Generated}

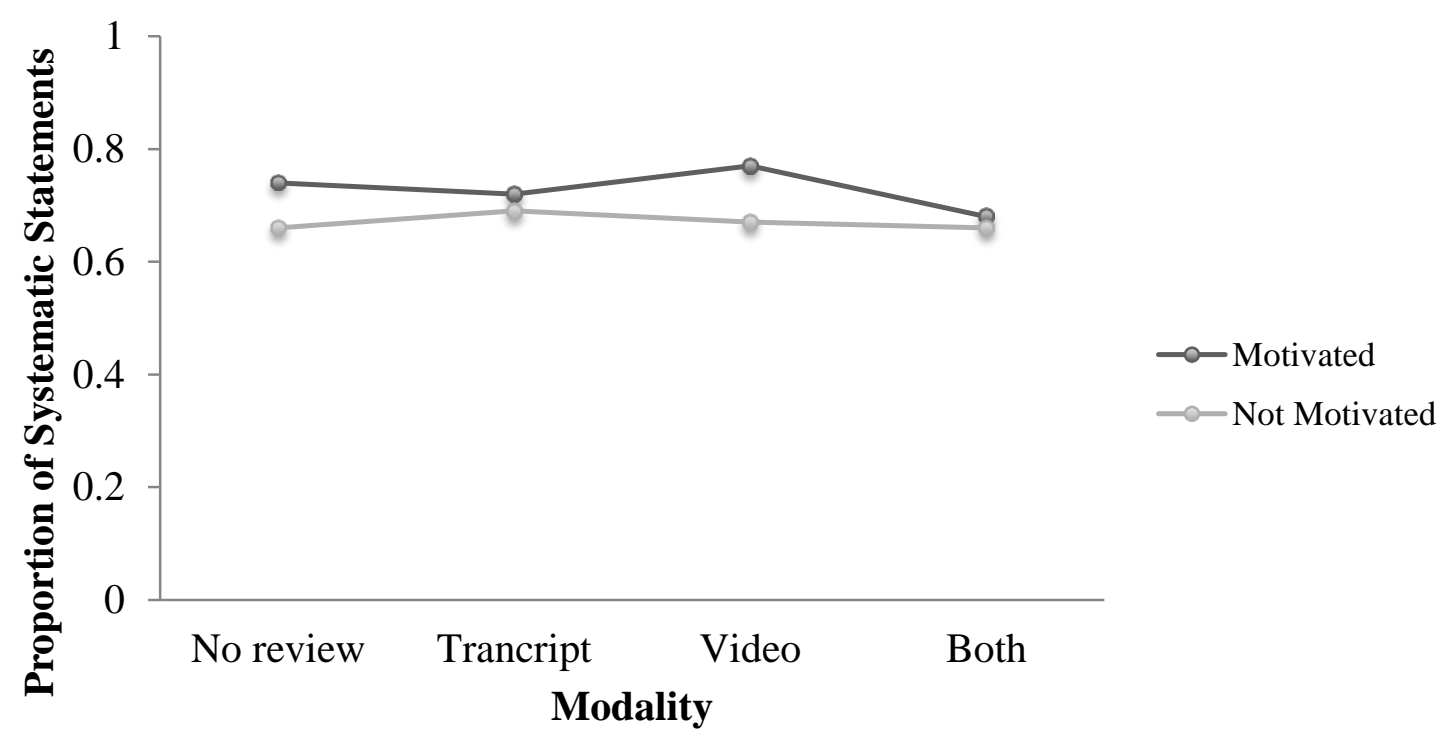

Figure 1. The proportion of systematic statements generated by participants. This figure displays the proportion of systematic statements generated by participants across the different conditions.

Ability to recall key aspects of the trial. Hypothesis three predicted that mock-jurors who were given the opportunity to review the trial would perform better on the memory task and correctly recall more trial details compared to participants who did not have the opportunity to review the trial, regardless of modality. On average, jurors across all conditions correctly 
recalled $80 \%$ of the trial's key aspects. An ANOVA was used to determine whether review modality affected participants' ability to recall trial information. No significant effect was found, $F(3,235)=1.19, p=.314$, partial $\eta^{2}=.015$. There was also no effect of motivation on recall scores, $F(1,235)=.028, p=.867$, partial $\eta^{2}=.000$ (see Figure 2). In addition, Need For Cognition scores were used as a predictor for overall recall ability. A reliability analysis of the Need for Cognition scores returned a Cronbach's alpha of .880, showing the scale to be highly reliable. Participants' scores ranged between 23 and 85, with an average score of 59.8. A simple linear regression analysis revealed that Need For Cognition $(\beta=-.045)$ did not predict recall ability, $F(1,241)=.497, p=.482, \mathrm{R}^{2}=.002$.

\section{Recall Ability}

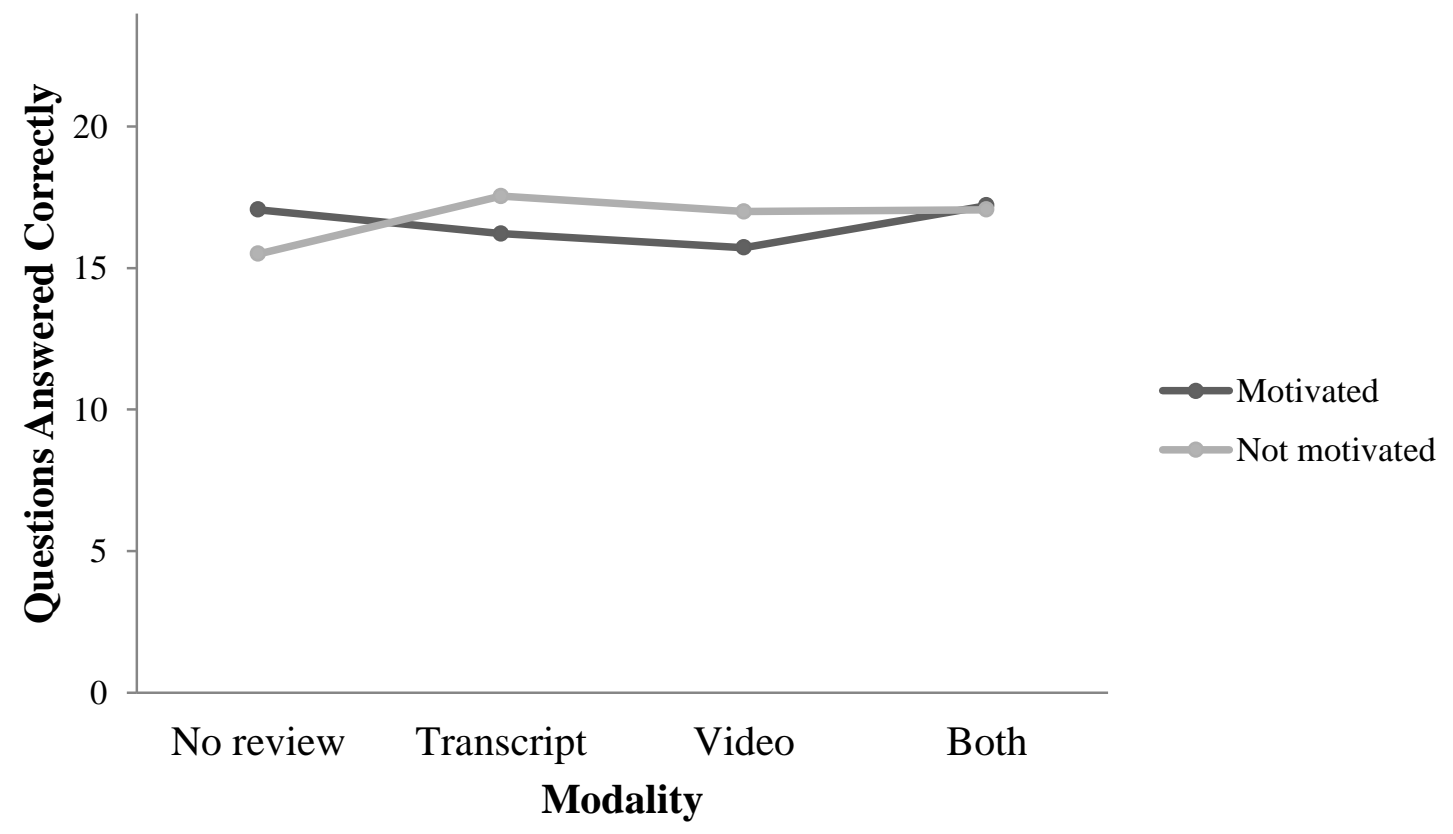

Figure 2. Average number of multiple-choice questions answered correctly. This figure shows the average number of multiple-choice questions participants answered correctly across the different conditions.

Review of materials - Sections reviewed. Participants who were given the opportunity to review the trial had access to the whole trial. For ease of review, the trial was divided up into 
13 sections, based on the number of people testifying in the trial. Within each condition, there was little variation in terms of the sections participants chose to review, except the expert witness and eyewitness testimony (see Table 2 for more detail). Additionally, for those who had access to both modalities, they generally spent their time using the transcript to review the trial.

There was a main effect for modality on the number of sections participants reviewed, $F$ $(2,181)=10.82, p<.001$, partial $\eta^{2}=.107$. Participants who used the transcript only $(\mathrm{M}=6.09$ sections, $\mathrm{SD}=.391)$ and those who had access to both forms of information $(\mathrm{M}=5.8$ sections, $\mathrm{SD}=.39)$ reviewed more sections than those who only had access to the video $(\mathrm{M}=3.6$ sections, $\mathrm{SD}=.42)$. However there was no main effect of motivation, $t(182)=1.619, p=.107$.

Review of materials - Time spent reviewing the trial. A significant effect of motivation on review time was found for participants who only used the video to review the trial, $t(55)=$ $2.23, p=.009$. Specifically, motivated participants spent more time reviewing the trial $(\mathrm{M}=6.9$ minutes, $\mathrm{SD}=2.37)$ compared to their not motivated counterparts $(\mathrm{M}=4.88$ minutes, $\mathrm{SD}=$ 3.03). No significant differences in terms of review time were found between motivated participants who used the transcript to review the trial $(\mathrm{M}=9.1$ minutes, $\mathrm{SD}=1.4$ minutes $)$ compared to their non-motivated counterparts ( $\mathrm{M}=8.5$ minutes, $\mathrm{SD}=2.2$ minutes) or between motivated participants who had access to both the video and the transcript $(\mathrm{M}=8$ minutes, $\mathrm{SD}=$ 2.8 minutes) compared to their non-motivated counterparts ( $\mathrm{M}=8.5$ minutes, $\mathrm{SD}=1.8$ minutes $)$. Additionally, a simple linear regression analysis revealed that Need for Cognition $(\beta=-.066)$ did not predict time spent reviewing the trial, $F(1,183)=.808, p=.370, \mathrm{R}^{2}=.004$. 
Table 2

Proportion of participants that reviewed each section by condition

\begin{tabular}{cccccccccccccc}
\hline $\begin{array}{c}\text { Modality } \\
\text { of review }\end{array}$ & 1 & 2 & 3 & 4 & 5 & 6 & 7 & 8 & 9 & 10 & 11 & 12 & 13 \\
\hline Transcript & $53 \%$ & $42 \%$ & $58 \%$ & $52 \%$ & $55 \%$ & $39 \%$ & $32 \%$ & $42 \%$ & $53 \%$ & $38 \%$ & $59 \%$ & $56 \%$ & $42 \%$ \\
Video & $33 \%$ & $32 \%$ & $53 \%$ & $44 \%$ & $19 \%$ & $26 \%$ & $14 \%$ & $23 \%$ & $26 \%$ & $19 \%$ & $30 \%$ & $19 \%$ & $23 \%$ \\
$\begin{array}{c}\text { Transcript } \\
\text { and video }\end{array}$ & $65 \%$ & $44 \%$ & $54 \%$ & $44 \%$ & $49 \%$ & $40 \%$ & $35 \%$ & $40 \%$ & $56 \%$ & $30 \%$ & $46 \%$ & $43 \%$ & $40 \%$ \\
\hline
\end{tabular}

Note. The numbers refer to the sections listed below.

1. Prosecution opening statement

2. Defense opening statement

3. Eyewitness testimony

4. Expert witness testimony

5. Carolyn King's testimony

6. David King's testimony (prosecution)

7. Cross examination of David King (defense)

8. James Prado

9. Michael McKown's testimony (prosecution)

10, Cross-examination of Michael McKown (defense)

11. James King's testimony (defense)

12. Cross examination of James King (prosecution)

13. Judge's instructions 
Verdict for murder and robbery. There was no significant association between the modality used to review the trial and participants' verdicts for the charge of murder, $\chi^{2}(3)=$ $7.49, p=.058$. There was also no significant difference between motivated participants and their non-motivated counterparts for the charge of murder, $\chi^{2}(1)=0.198, p=.657$. For the charge of murder, $58 \%$ of participants judged King as not guilty, while $42 \%$ of participants judged him as guilty. There was no difference in conviction rates between the conditions (see Table 3 for conviction rates by review modality).

Table 3

Murder conviction rates

\begin{tabular}{ccc}
\hline $\begin{array}{c}\text { Review } \\
\text { modality }\end{array}$ & $\begin{array}{c}\text { Proportion of not } \\
\text { guilty verdict }\end{array}$ & $\begin{array}{c}\text { Proportion of guilty } \\
\text { verdicts }\end{array}$ \\
\hline No review & $64 \%$ & $36 \%$ \\
Transcript & $50 \%$ & $50 \%$ \\
Video & $70 \%$ & $30 \%$ \\
Video and & $51 \%$ & $49 \%$ \\
transcript & & \\
\hline
\end{tabular}

Additionally, there was no interaction between modality and motivation in participants' verdicts for murder, $\chi^{2}(3)=1.36, p=.715$. However, there was a difference in the ratings of how likely participants thought King was of being guilty between the different review modality conditions, $F(3,235)=2.79, p=.041$, partial $\eta^{2}=.034$. A post hoc Tukey test revealed that participants who had access to both forms of information $(\mathrm{M}=4.14, \mathrm{SD}=1.42)$ viewed King as guiltier than those in the video only condition $(\mathrm{M}=3.47, \mathrm{SD}=1.24)$. There was no significant difference between participants in the transcript $(\mathrm{M}=3.89, \mathrm{SD}=1.23)$ and no review $(\mathrm{M}=3.63, \mathrm{SD}=1.47)$ conditions. There were also no significant differences between those in the: transcript and video conditions, video and no review conditions, transcript and both conditions, or between those who had access to both modalities and their no review counterparts. Participants were equally 
confident in their verdict for murder, regardless of modality, $F(3,235)=.562, p=.641$, partial $\eta 2=.007$

There was no significant association between the modality used to review the trial and participants' verdicts for charge of robbery, $\chi 2(3)=4.54, p=.209$; nor was there a difference between motivated and non-motivated participants and their verdict for robbery, $\chi 2(1)=0.152$, $p=.697$. For the charge of robbery, $57 \%$ of participants judged King as not guilty, while $43 \%$ of participants judged him as guilty. There was no difference in conviction rates between the conditions (see Table 4 for conviction rates by review modality).

Table 4

Robbery conviction rates

\begin{tabular}{ccc}
\hline $\begin{array}{c}\text { Review } \\
\text { modality }\end{array}$ & $\begin{array}{c}\text { Proportion of not } \\
\text { guilty verdict }\end{array}$ & $\begin{array}{c}\text { Proportion of guilty } \\
\text { verdicts }\end{array}$ \\
\hline No review & $62 \%$ & $38 \%$ \\
Transcript & $52 \%$ & $48 \%$ \\
Video & $67 \%$ & $33 \%$ \\
Video and & $51 \%$ & $41 \%$ \\
transcript & & \\
\hline
\end{tabular}

For the charge of robbery, there was no interaction between modality and motivation in participants' verdicts for robbery, $\chi 2(3)=.682, \mathrm{p}=.877$. There was also no significant difference in the likelihood ratings of guilt for modality, $F(3,235)=1.59, p=.191$, partial $\eta^{2}=$ .020. Last, there was no difference in participants' confidence ratings for the modality used to review the trial, $F(1,235)=.012, \mathrm{p}=.914$, partial $\eta 2=.000$. 


\section{Discussion and Summary}

Broadly, the current study examined whether the modality of information available during the decision-making period affected the juror decision-making process. Results of the current study indicated that having the opportunity to review evidence prior to rendering a verdict did not affect the way in which mock-jurors process information. Additionally, mockjurors' verdicts were unaffected by the modality used to review the trial or whether they received explicit instruction regarding the task importance. The present research sought to answer three main questions. The first explored the relationship between motivation and the way in which information is processed. The second explored the effect of review modality on information processing. The third explored the effect of review modality and motivation on participants' ability to recall key aspects of the trial.

\section{The Effect of Motivation on the Proportion of Systematic Statements Generated}

A primary goal of this research was to explore how manipulating mock-jurors' level of motivation would affect how they processed information. Previous research has found that when task engagement levels are increased, information tends to be processed systematically as opposed to heuristically (Chaiken, 1980). In line with Chaiken's (1980) findings, a trend indicated that participants who were in the motivated condition produced more systematic statements compared to the unmotivated participants. Generally, mock-jurors processed the information systematically, regardless of whether motivation was manipulated or not. This finding is due, in part, to participants perceiving the task as interesting, as indicted by their high PTI scores. As most participants rated high on the PTI scale there was little variance within the measure, which also contributed to the non-significant finding. Perhaps with more variability on the PTI rating an effect would have been detected. 
Despite participants perceiving the trial as important, it is crucial to understand how these results relate to non-student samples. In the case of a murder trial, it has been found that mock jurors were more likely to find the defendant not guilty than actual potential jurors (Simon \& Mahan, 1971). However, in a review of the literature, Bornstein (1999) found that students did not significantly differ from non-student samples on their judgments in the vast majority of studies analyzed. Although the studies reviewed in Bornstein's paper did not involve manipulating mock jurors' level of motivation, they indicated that mock-jurors were a suitable sample to use when examining juror decision-making. Participants' high ratings of their perceived task importance further support the suitability of using mock-jurors in jury decisionmaking studies. As a result, we can assume that actual jurors would be naturally motivated when fulfilling their civic duty as a juror and are therefore, as hoped, are likely to process information systematically.

In relation to the statements generated by participants, it is interesting to note that there were many instances where mock-jurors suggested that innocent people do not need alibis and therefore seeking an alibi is an indicator of guilt. This finding is cause for concern, as we know that an alibi is a way of demonstrating that an individual could not have committed a given crime, as they were elsewhere at the time the crime was committed (Culhane \& Hosch, 2012). Despite jurors generally processing information systematically, they were also making grave misjudgments of legal information, supporting the idea that we cannot assume people understand what alibis are. Since jurors may misunderstand the nature of alibis and other legal concepts, it may be advisable to educate them on the legal process and to ensure comprehension of trial content with legal terms being converted to lay persons terminology. This has become common 
practice for English and Welsh Jurors who are educated on procedural information prior to the start of the trial (Haralambous, 2010).

Educating jurors is likely to be the best strategy to reduce misunderstandings of legal information or terms, as the present findings indicate that they do generally perceive the task as important and are processing information systemically. As a result, it is likely that instructions given to jurors will be listened to and thought about, which is what we hope they are doing throughout the trial. On the other hand, the cost associated with educating jurors could be high, as their duties only last the course of the trial and new juries would therefore need to be educated for each trial. However, the cost of a mistrial or a wrongful conviction is also very high, in all senses of the term.

\section{The Effect of Modality on the Proportion of Systematic Statements Generated}

The second hypothesis was not supported and no difference was found in the proportion of systematic arguments provided between participants in the different review conditions. This finding diverges from previous literature, which suggests that modality does impact the way in which information is processed (Salomon, 1984; Sundar, 2000; Davis et al. 2006). One reason for this finding is perhaps that participants perceived the task as important, which led them to process information systematically, regardless of the modality used to review the evidence. Their high PTI scores support this explanation. Applied to the courtroom, this is a positive finding, as it does not seem as though jurors will be heavily influenced by the form information is presented in. 


\section{Recall of Trial Information}

One explanation for participants obtaining relatively high scores on the memory questionnaire is that they paid attention, as suggested by their high PTI scores. Alternatively, the questions may have been too easy, which would have resulted in a ceiling effect. As a result, the differences in recall ability may not have been detected as a function of having the opportunity to review the trial or not. Furthermore, a different memory assessment tool, such as free recall, might have been better suited, as it would probably produce more variation in responses. Having two independent assessments of memory for the trial events would have given us a clearer understanding of the effects that reviewing the trial might have on memory. Overall, the memory questions being asked in this study were shown to be easy, as only four of the questions allowed for discrimination between participants who did well overall and those who did not.

Additionally, the need for cognition scale was not a good predictor of one's ability to recall trial events. One likely explanation is that an educated sample was used, as indicated by Need for Cognition scale, where the baseline score was high; meaning, participants rated themselves as enjoying cognitively demanding tasks. In conjunction with the multiple-choice questions being easy and participants' high ratings on the Need for Cognition scale, there was little variation within the measures. Consequently, there was not enough power to detect any effects.

\section{Review of Materials}

Participants in the video only condition reviewed fewer sections compared to those who had access to a transcript. This finding may be due in part to participants perceiving the video as requiring less effort. Sundar (2000) suggested that the use of videos might cue people to automatically process information in contrast to written material. This may cause people to pay 
less attention to the information being presented. In the current context, participants who reviewed the video could have considered it as a task that did not require a lot of attention and put less effort into assessing the content. Alternatively, it may have been faster for participants to read the transcripts than to watch an equivalent amount of "information". With that said, these difference did not seem to alter verdicts in any way.

It is interesting to note that participants who were given the option of using a transcript and/or the trial video generally chose the transcript to complete their review. This is particularly remarkable, as past research has indicated that individuals perceived videos as being easier to learn from compared to text (Choi \& Johnson, 2005). If so, it would then follow that jurors would be more likely to review the trial using the video, but this is not what we found. Participants may have opted for the transcript because they felt as though they were able to get a deeper understanding of the trial information, as has been demonstrated in the literature.

However, I believe more research is needed to explore this effect and I would also suggest that it may be linked to the fact that mock-jurors had already seen the trial video and therefore, did not see the value in reviewing it using the same modality.

\section{Verdict Decisions}

Although the quantity of material participants chose to review varied depending on the condition they were in, their verdict did not. In addition, there was a statistical difference in participants' ratings for how guilty they believed King was of murder, however, the effect size was quite small. Participants were also equally confident in their verdict across all conditions. Participants may have found the trial easy to remember and as a result, no matter how much they reviewed, their baseline understanding of the evidence was high. 


\section{Limitations}

There are a number of limitations and future directions that must be considered. First, there was a discrepancy between the demographic characteristics of the current sample and that of the population. Specifically, the current sample was comprised of university students whose median age was 19 and were predominantly female, compared to the general population where the median age is 40 years old and only $64 \%$ have post-secondary qualifications (Statistics Canada, 2012; Statistics Canada, 2011). While this may not be overly problematic, it is not representative of the criminal justice system. For example, Anwar, Bayer, and Hjalmarsson (2013) found that prosecutors in the United States are more likely to exclude younger members of the jury pool compared to the defense who is more likely to exclude older members of the jury pool. These findings suggest that younger jurors are more likely to arrive at a not guilty verdict compared to their older counterparts. As a result, researchers should be mindful of sample demographics.

Second, participants may have found it easier to remember key aspects of the trial used in the current study as they viewed an abbreviated version of it. Therefore, the quantity of information they were asked to remember was far less than that of the full trial. As a result, their memory of the trial events could have changed had they been asked to remember more information and this could have altered what they chose to review as well as their verdicts. Before guidelines are developed, more research is needed using full-length trials.

Third, the ecological validity of the study was challenged as there were time constraints placed upon mock-jurors, whereas in the legal system jurors are not bound by these constraints. For example, mock-jurors in the current study were only given 10 minutes to review the evidence and were then asked to provide their verdict; compared to the legal system, where 
jurors are given as much time as they need to deliberate and potentially review the evidence. As this issue will be ongoing when conducting experiments in the laboratory, future research may wish to explore the use of actual jurors as participants.

Fourth, the generalizability of the results was threatened as participants were asked to make individual decisions, whereas in an actual trial, jurors are given time to discuss the information as a panel. Although we were interested in the individual effects that technology had on the decision-making process of mock-jurors, in the justice system, jurors deliberate, and this dynamic may affect the degree to which the modality of information affects juror's decisions. Future research should use groups of mock-jurors and allow them to deliberate while giving them access to various forms of information.

\section{Future Directions}

Future research should continue to explore the effects of motivation on jury deliberations and their willingness to invest resources in completing the task. For example, perhaps the act of deliberating with others would change the dynamic of jurors and their levels of motivation, and they would review the trial differently than if they were alone. Possible pressure from their peers to arrive at a decision may also change the way they perform their review or the time taken to do so.

Future research should also consider using fabricated live trials as this may impact mockjurors' willingness to use different forms of technology. For example, mock-jurors who watched a video of a trial (as in the present study) may be less likely to use a video of the trial to review the evidence as they have already watched the trial in that form. Using a fabricated live trial would be a more realistic representation of an actual trial. 
Last, future directions should explore how the use of different devices and file indexing affect mock-jurors willingness to review trial evidence. The goal of this would be to determine whether reviewing the trial passively (e.g. watching a video) or being an active juror (e.g. manipulating evidence) impacts jurors' decisions. In doing so, we will be able to get a better understanding of the extent to which the jury evidence recording platform may affect jurors' decisions.

\section{Conclusion}

The use of technology has become increasingly prevalent within courtrooms. Research is unclear on the effects that using technology during the decision-making period of a trial might have on the way information is being processed and ultimately, on jurors' verdicts. One factor that has been associated with increasing the likelihood of information being processed in a systematic fashion is motivation, however, this has never been applied in a forensic setting. The current research presents a new path to help understand the effects of motivation and use of technology during the decision-making period of a trial and the effects it has on the ways in which jurors process information. Current findings suggest that mock-jurors were highly motivated, provided a high proportion of systematic arguments to support their verdict, and their verdicts did not change as a result of being able to review the trial. However, those who were given the opportunity to review the trial, preferred to use the transcript compared to the video.

Practically, these findings indicate that we should be ensuring that jurors are engaged, as this was predictive of the proportion of systematic statements participants provided. Second, given jurors' preference towards the transcript when reviewing the trial, courts should take this into account when deciding which forms of evidence are most appropriate for jurors to review. 
In conjunction with the criminal justice system, we, as a field, should continue to research the issue at hand and help develop a concrete set of guidelines with regards to reviewing information during the deliberation period. The development of guidelines will help us to standardize the deliberation component of the trial - in terms of the form of information jurors are allowed to use during their deliberations - which will help to ensure the equality of deliberations from courtroom to courtroom and across the country. 


\section{Appendices}

\section{APPENDIX A: CODING GUIDE}

The following are categories that statements may fall under. Please assess each statement and decide which category it falls under. Once you have assessed the statement, please place the correct code next to that statement in the doc file (can also be in hard copy).

Guidelines:

- If given the same reason within the same cell (refer to word doc) only mark the first statement and highlight the second statement in green

- There could be multiple codes per cell depending on the information provided (e.g. each participant may have different codes within the same cell)

- Code irrelevant information as " 0 " but highlight the statement

- Break down sentences with multiple pieces of information

- If participant is qualifying/ explaining reasoning don't code twice

Systematic - argument based categories and codes: Internal to the case/ analyzing (analyze $\underline{\text { trial within itself) }}$

$>1$ - Strength of evidence -- physical evidence

○ Based on legal parties knowledge

- Time line of events

$\circ$ Finger prints not matching

$>2$ - Persuasive arguments/ or not -testimony

○ Based on lawyers argument

- Based on witness argument

If its truthful, it's persuasive

3 - Fact based arguments

- Based on event that were known (concrete)

- Not about evidence. Treat as fact but that's not evidence.

4 - Other

- Anything that does not fall under the above categories but is systematic (i.e. logic shown)

Heuristic - source based categories and codes: External to the case/ inference (simple inferential rules) 
5 - Personal characteristics (witness, defendant, and lawyers)

○ Attributes -judgment of character

- King looked like... honest, liar...

- Did not seem truthful

- He seems suspicious

6 - Face value statements/ overreliance on credentials

○ Could be based on credentials

7 - consensus/ overreliance on numbers

○ Everyone said...

$>8$ - statements based on participants' prior knowledge (whether it be true or false) judgment call

- Statements that participants would know nothing about or that they are using prior knowledge in a meaningless fashion

- When people lie their eyes move a lot

- Sons needed money

- He needed money for Vegas because it costs a lot

9 - Veracity of the statement/ judgment about truth

- When a statement is given that is based on the accuracy of the argument, not the strength of the argument. (if based on strength of argument put as 2)

- Seems weird about testimony

- Strange

- Too good to be true

\section{$\underline{3^{\text {rd }} \text { category: Statements that cannot be classified }}$}

Meaningless statements ( $3^{\text {rd }}$ category)

10 - Statements that can't be categorized

\section{$\underline{4}^{\text {th }}$ category: nothing written}

0 - didn't write anything 
APPENDIX B: MULTIPLE-CHOICE QUESTIONS

* Indicate items deleted

1) How long did James King work at the bank for?
A. Less than 5 years
B. Between 6 and 10 years
C. Between 11 and 15 years
D. More than 16 years

2) When James King went downtown on the day of the robbery, where did he claim to have gone?
A. The chess club
B. The bank to get a larger safety deposit box
C. The grocery store
D. To do some cloths shopping

3) Before working at the bank, what did James King do for a living?
A. Police officer
B. Security guard
C. Armored transportation guard
D. All of the above

4) In which city did the crime occur?
A. Denver, Colorado
B. Dacano, Colorado
C. Denton, Georgia
D. Dennis, Massachusetts

5) How many guards were killed during the commission of the crime?
A. 2
B. 4
C. 6
D. 8

6) What kind of gun was used during the commission of this crime?
A. Revolver
B. Shotgun
C. Rifle
D. None of the above 
7) According to Maria Christian's (eyewitness) testimony, where did the suspect tell her to go at first?
A. The man trap
B. The vault
C. The atrium
D. The guard's room

*8) According to the State's witness, how many different types of guns could have possibly matched the bullet (s) found at the crime scene?
A. Less than 2
B. 3-4
C. More than 7
D. Cannot remember

*9) When did James King get a larger safety deposit box at the bank?
A. The day after the robbery
B. The day before the robbery
C. A couple of months before the robbery
D. A couple of months after the robbery

10) What was on the side of James King's face during the trial?
A. Mole
B. Cut
C. Band-Aid/ dressing
D. Blister

11) What type of facial hair did Michael McKown (guard and friend) have when testifying in court?
A. Moustache
B. Beard
C. Goatee
D. None of the above

12) What was the relationship status of James King?
A. Married
B. Single
C. Common law partner
D. Divorced 
13) What color dress was Nina McGinty (eyewitness) wearing when she first testified?
A. Yellow
B. Blue
C. Black
D. Grey

14) What kind of money did Kenetha Whisler (eyewitness) say the assailant demanded from her during the robbery?
A. Strapped bills
B. Loose bills
C. Change
D. Bank money

15) What floor of the parking garage did the employees use?
A. 4
B. 5
C. 6
D. 7

16) Where were three of the guards murdered?
A. Guard monitor room
B. Bank's Atrium
C. Bank's Vault
D. The man trap

*17) On the day after the robbery how many times did King go to the bank?
A. 1
B. 2
C. 3
D. 4

18) On the day of the murder and robbery, where did the hostages go after leaving the man trap?
A. The bank's Atrium
B. The vault
C. The guard's monitor room
D. Underneath the desk outside the vault 
19) During the trial, when did Carolyn King (wife) testify?
A. After detective Frank Kerber's testimony
B. After James King testified
C. After David King testified
D. After James Prado (Supervisor of bank guards) testified

*20) In how many police identification photographs did James King have a moustache?
A. 0
B. 1
C. 2
D. 3

21) How did James King dispose of his gun?
A. In the trash
B. At the gun shop
C. Gave it back to his employer
D. Gave it to his son

22) Where did James Prado (Guard supervisor) describe the key holder to be located?
A. In the guard monitor room next to the window looking in the man trap
B. In the guard monitor room between the shelves and the desk
C. In the guard monitor room by the microwave
D. In the guard monitor room behind the desk

23) After shooting his gun on the job in June of 1990 King cleaned his gun, what did he notice while cleaning it?
A. It had a cracked cylinder
B. The firing pin was broken
C. Nothing was wrong
D. I don't remember

24) On Father's day (June $\left.16^{\text {th }}, 1991\right)$, what did James King say he did immediately after eating breakfast?
A. Yard work
B. Playing chess
C. Go to the cemetery
D. Go to the bank 
25) Who was the last person to testify during the trial?
A. James King
B. David King
C. Carolyn King
D. Michael McKown 


\section{APPENDIX C: PERCEIVED TASK IMPORTANCE QUESTIONNAIRE}

1) To what extent did you find the task interesting?

Very

uninteresting

2) How important was it for you to pay attention to all the facts presented during the trial?

Unimportant

3) How enjoyable did you find the task?

Not

Enjoyable enjoyable

4) How important is it for real jurors to pay attention to all the facts?

Unimportant

Important

5) To what extent were you focused on the information presented during the trial?

Not

Focused focused

6) To what extent do you think it is important to investigate juror decision-making?

Unimportant

Important

7) To what extent do you think the results from this study will be useful?

Very

Very useless useful 
APPENDIX D: TRIAL INDEX - TRANSCRIPT

Review

$\underline{\text { Section }}$

$\underline{\text { Review }}$

William Buckley opening statement

Scott Robinson opening statement

Eyewitness testimony

Expert witnesses testimony

Carolyn King's testimony

David King's testimony (prosecution)

Cross examination of David King (defense)

James Prado

Michael McKown's testimony

(prosecution)

Cross examination of Michael McKown

(defense)

James King's testimony (defense)

James King's testimony (prosecution)

Judge's instructions 


\section{APPENDIX E: TRIAL INDEX - VIDEO}

$\underline{\text { Time }}$

0:00

$3: 37$

$5: 33$

8:09

$8: 56$

$14: 46$

$16: 33$

$17: 39$

$18: 50$

$22: 10$

$23: 43$

$34: 31$

$42: 42$ $\underline{\text { Section }}$

$\underline{\text { Review }}$

William Buckley opening statement

Scott Robinson opening statement

Eyewitness testimony

Expert witnesses testimony

Carolyn King's testimony

David King's testimony (prosecution)

Cross examination of David King (defense)

James Prado

Michael McKown's testimony (prosecution)

Cross examination of Michael McKown (defense)

James King's testimony (defense)

James King's testimony (prosecution)

Judge's instructions 
APPENDIX F: TRIAL INDEX - BOTH

$\underline{\text { Time }}$

$\underline{\text { Section }}$

$\underline{\text { Review video }}$

$\underline{\text { Review transcript }}$

0:00 William Buckley opening statement

$3: 37$

Scott Robinson opening statement

5:33 Eyewitness testimony

8:09 Expert witnesses testimony

8:56 Carolyn King's testimony

14:46 David King's testimony (prosecution)

16:33 Cross examination of David King (defense)

$17: 39$

James Prado

18:50

Michael McKown's testimony (prosecution)

$22: 10$

Cross examination of Michael McKown (defense)

23:43 James King's testimony (defense)

$34: 31$

James King's testimony (prosecution)

Judge's instructions 


\section{References}

Anwar, S., Bayer, P., \& Hjalmarsson, R. (Working paper). The role of age in jury selection and trial outcomes. National Bureau of Economic Research, Inc. doi: 10.3386/w17887

Bornstein, B. H. (1999). The ecological validity of jury simulations: Is the jury still out? Law and Human Behavior, 23(1), 75-91. doi: 10.1023/a:1022326807441

Cacioppo, J., \& Petty, R. (1982). The need for cognition. Journal of Personality and Social Psychology, 42, 116-131. doi: 10.1037/0022-3514.42.1.116

Cacioppo, J., \& Petty, R. (1984). The elaboration likelihood model of persuasion. Advances in Consumer Research, 11, 673-675.

Cacioppo, J., Petty, R., \& Kao, C. F. (1984). The efficient assessment of need for cognition. Journal of Personality Assessment, 48(3), 306-307. doi. 10.1207/s15327752jpa4803_13

Chaiken, S. (1980). Heuristic versus systematic information processing and the use of source versus message cues in persuasion. Journal of Personality and Social Psychology, 39(5), 752-766. doi: 10.1037/0022-3514.39.5.752

Chaiken, S., \& Maheswaran, D. (1994). Heuristic processing can bias systematic processing: Effects of source credibility, argument ambiguity, and task importance on attitude judgment. Journal of Personality and Social Psychology, 66(3), 460-473. doi: $10.1037 / 0022-3514.66 .3 .460$

Choi, H., \& Johnson, S. (2005). The effect of context-based video instruction on learning and motivation in online courses. American Journal of Distance Education, 19(4), 215227. doi:10.1207/s15389286ajde1904_3 
Culhane, S. E., \& Hosch, H. M. (2012). Changed alibis: Current law enforcement, future law enforcement, and layperson reactions. Criminal Justice and Behavior, 39, 958-977. doi:10.1177/0093854812438185

Davis, M., Markus, K. A., \& Walters, S. B. (2006). Judging the credibility of criminal suspect statements: Does mode of presentation matter? Journal of Nonverbal Behaviour, 30(1), 181-198. doi: 10.1007/s10919-006-0016-0

DePaulo, B. M., Lanier, K., \& Davis, T. (1983). Detecting the deceit of the motivated liar. Journal of Personality and Social Psychology, 45, 1096-1103.

Ellsworth, P. C. (1989). Are twelve heads better than one? Law and Contemporary Problems, 52(1), 205-224. doi: 10.2307/1191911

Farrell, R (2014). Jury evidence recording system. Retrieved from: http://www.mad.uscourts.gov/attorneys/pdf/JERS\%20attorney\%20instructions.pdf

Haralambous, N. (2010). Educating jurors: Technology, the Internet and the jury system. Information \& Communications Technology Law, 19(3), 255-266. doi: $10.1080 / 13600834.2010 .533454$

Landis, J. R., \& Koch, G. G. (1977). The Measurement of Observer Agreement for Categorical Data. Biometrics, 33(1), 159-174. doi: 10.2307/2529310

Park, J., \& Feigenson , N. (2013). Effects of a visual technology on mock juror decision making. Journal of Applied Cognitive Psychology, 27(1), 235-246. doi: 0.1002/acp. 2900

Salomon, G. (1984). Television is "easy" and print is "tough": The differential investment of mental effort in learning as a function of perceptions and attributions. Journal of Educational Psychology, 76(4), 647-658. doi: 10.1037/0022-0663.76.4.647 
Simon, R. J., \& Mahan, L. (1971). Quantifying Burdens of Proof: A View from the Bench, the Jury, and the Classroom. Law \& Society Review, 5(3), 319. doi: 10.2307/3052837

Statistics Canada. (2011). Education in Canada: Attainment, field of study and location of study. (National Household Survey Publication No. 99-012-X2011001). Ottawa, Ontario.

Statistics Canada. (2012). Annual demographic estimates: Canada, provinces and territories. (Publication No. 91- 215- X). Ottawa, Ontario.

Sundar, S. (2000). Multimedia Effects on Processing and Perception of Online News: A Study of Picture, Audio, and Video Downloads. Journalism \& Mass Communication Quarterly, 77(3), 480-499. doi: 10.1177/107769900007700302

The National Justice Institute. (2012). Retrieved from: https://www.njiinm.ca/index.cfm/publications/model-jury-instructions/finalinstructions/deliberations/transcript-of-evidence/

Todorov, A., Chaiken, S., \& Henderson, M. (2002). The Heuristic-Systematic Model of Social Information Processing. In The Persuasion handbook developments in theory and practice (pp. 195-211). California: Sage Publications. 